\title{
Two-step endoscopic ultrasound-guided drainage of an isolated posterior bile duct because of an enlarged gallbladder
}

An 83-year-old man with hilar cholangiocarcinoma who had undergone multiple metal stent placements for hilar biliary obstruction 15 months previously was admitted to our hospital for treatment of cholangitis. Contrast-enhanced computed tomography revealed dilatation of the right posterior duct, indicating that the isolated posterior duct was causing focal cholangitis.

First, we attempted biliary drainage using endoscopic retrograde cholangiopancreatography (ERCP), but this failed because a guidewire could not be passed through the metal stent. Subsequently, we planned endoscopic ultrasound-guided biliary drainage (EUS-BD) of the duct from the duodenal bulb; however, avoiding the enlarged gallbladder to puncture the posterior duct under EUS guidance was impossible ( $\mathbf{F i g . 1}$ a). We therefore placed a 6-Fr nasocystic drainage tube under EUS guidance in an attempt to improve the situation ( $\vee$ Fig. $\mathbf{1}$ b). After 4 days, the gallbladder had shrunk, and the interposed gallbladder between the EUS and posterior duct had disappeared ( $\triangleright$ Fig.2). We punctured the posterior duct using a $19 \mathrm{G}$ needle, inserted a guidewire, dilated a tract, and then placed a covered metal stent that was $10 \mathrm{~mm}$ in diameter and $6 \mathrm{~cm}$ in length with a 1-cm uncovered portion at the distal end (bare-end type, Niti-S biliary S-type; Taewoong Corporation, Seoul, Korea) ( $\triangleright$ Fig.3), with successful drainage of pus ( $>$ Fig. 4 ; $>$ Video 1 ). The patient's cholangitis improved following the procedure, and there was no reoccurrence in the next 4 months.

EUS-BD for isolated right hepatic duct (RHD) obstruction was recently reported [1]; however, an enlarged gallbladder that is interposed between the echoendoscope and the target duct sometimes hampers the procedure. This situation may arise where cancer is invading
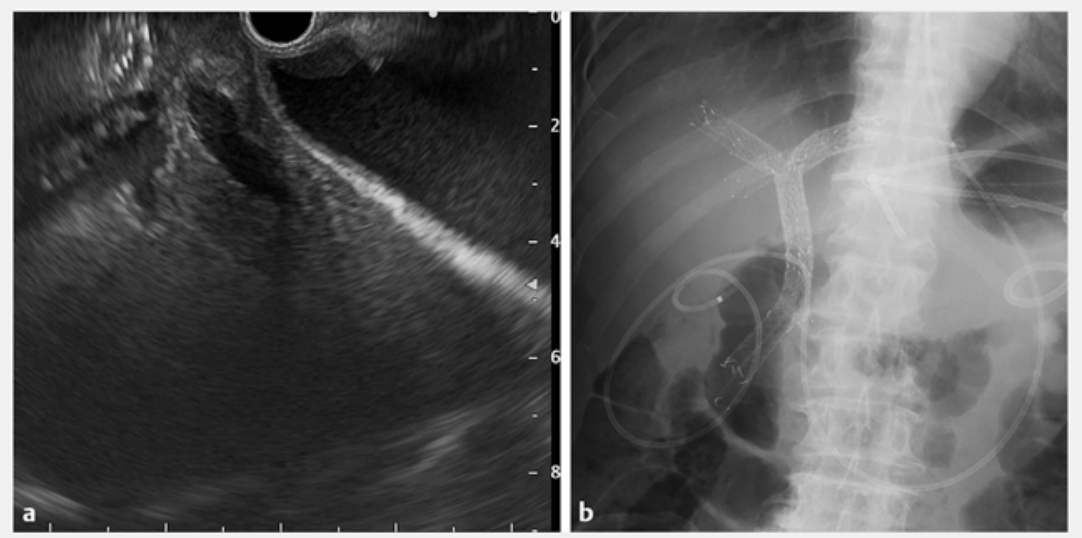

- Fig. 1 Radiographic images showing: a the impossibility of puncturing the right posterior duct under endoscopic ultrasound (EUS) guidance owing to the interposed enlarged gallbladder; $\mathbf{b}$ a nasocystic drainage tube that was placed into the enlarged gallbladder under EUS guidance.

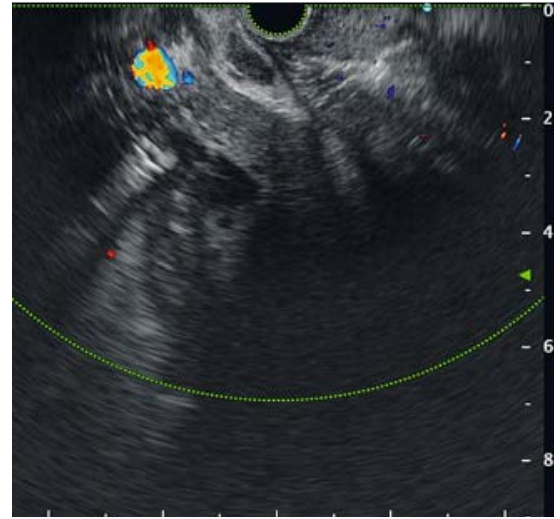

- Fig. 2 Endoscopic ultrasound image showing that the gallbladder had shrunk and the interposed gallbladder disappeared after the nasocystic drainage tube had been in place for 4 days.

the cystic duct. In such cases, drainage of the gallbladder under EUS guidance can facilitate EUS-BD of the RHD, and the strategy should be considered as a potential method of troubleshooting for EUS-guided isolated RHD drainage. The method helps avoid percutaneous drain-

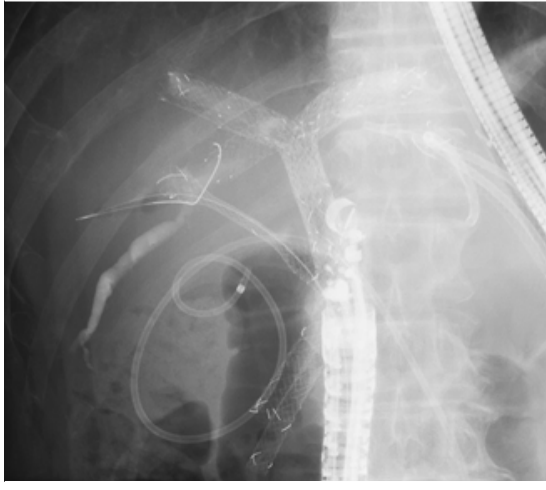

- Fig. 3 Radiographic image showing placement of a metal stent under fluoroscopic guidance after the posterior duct had been punctured under endoscopic ultrasound guidance.

age, which is known to lead to a deterioration in quality of life for advanced cancer patients.

Endoscopy_UCTN_Code_TTT_1AS_2AG 


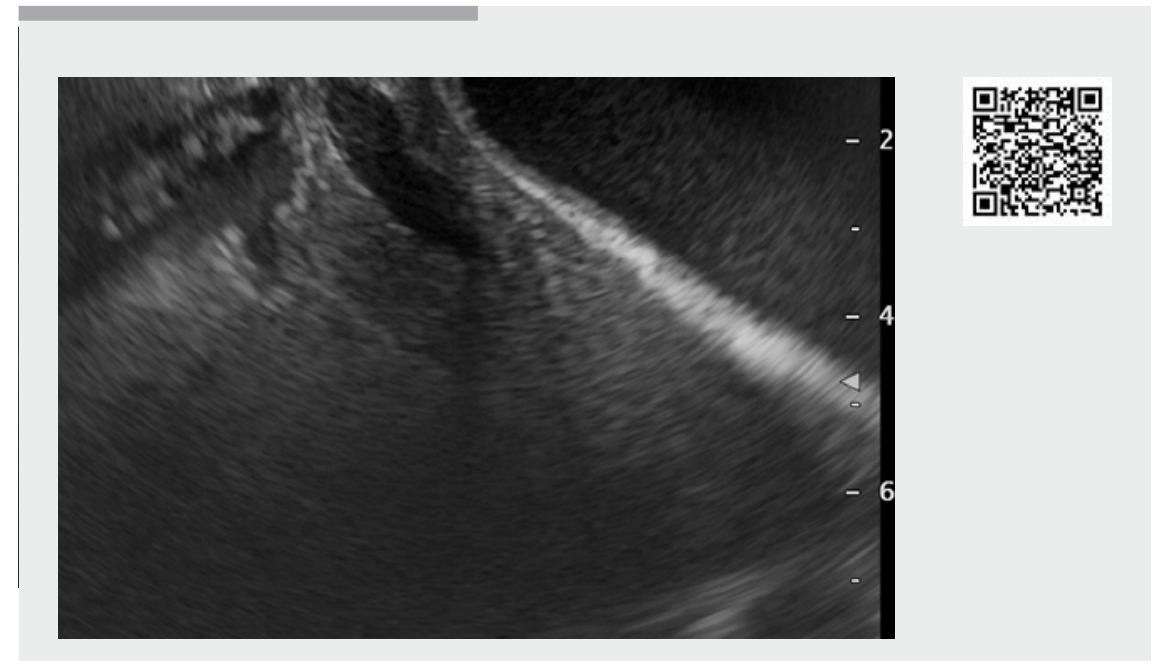

$\checkmark$ Video 1 The enlarged gallbladder is shown hindering access to the right posterior duct; however, endoscopic ultrasound (EUS)-guided drainage of the duct was successful after EUS-guided gallbladder drainage.

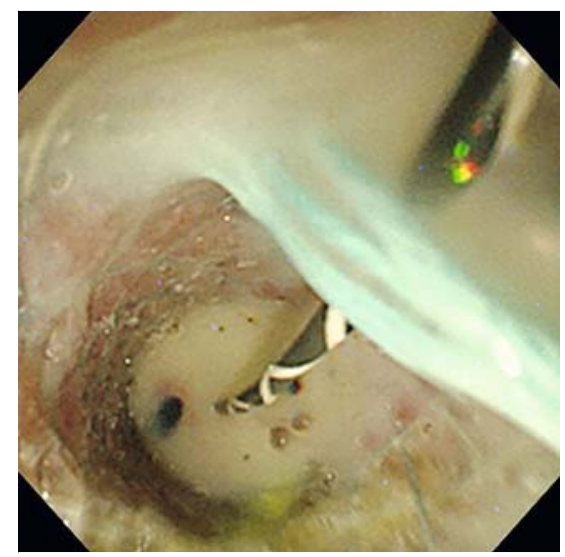

Competing interests

None

The authors

Junya Sato ${ }^{1}$, Hirotoshi Ishiwatari ${ }^{1}$, Tatsunori Satoh', Shinya Fujie', Junichi Kaneko', Hiroyuki Matsubayashi ${ }^{1,2}$, Hiroyuki Ono ${ }^{1}$

1 Division of Endoscopy, Shizuoka Cancer Center, Shizuoka, Japan

2 Familial Cancer Clinic, Shizuoka Cancer Center, Shizuoka, Japan
Corresponding author

Hirotoshi Ishiwatari, MD, PhD

Division of Endoscopy, Shizuoka Cancer Center, 1007 Shimonagakubo Nagaizumicho, Sunto-gun, Shizuoka, Japan ishihiro481019@gmail.com Fax: +81-55-9895551

\section{Reference}

[1] Park SJ, Choi JH, Park DH et al. Expanding indication: EUS-guided hepaticoduodenostomy for isolated right intrahepatic duct obstruction (with video). Gastrointest Endosc 2013; 78: $374-380$

\section{Bibliography}

DOI https://doi.org/10.1055/a-0929-4182

Published online: 7.6.2019

Endoscopy 2019; 51: E347-E348

(c) Georg Thieme Verlag KG

Stuttgart · New York

ISSN 0013-726X

\section{ENDOSCOPY E-VIDEOS \\ https://eref.thieme.de/e-videos}

回的回 Endoscopy E-Videos is a free 亩臹: access online section, reporting on interesting cases and new

techniques in gastroenterological endoscopy. All papers include a high quality video and all contributions are freely accessible online.

This section has its own submission website at

https://mc.manuscriptcentral.com/e-videos 